\section{Reseña de Más allá de las lágrimas. Espacios habitables en el cine clásico de México y Argentina, de Isaac León Frías}

\author{
Ángel Miquel \\ miquel@uaem.mx
}

Universidad Autónoma del Estado de Morelos, México

https://doi.org/10.32870/ elojoquepiensa.v0i19.317
Fruto de una acuciosa investigación, en esta obra se ofrecen innumerables datos acerca de las dos cinematografías más destacadas de Latinoamérica en el periodo de aproximadamente treinta años que inicia con la edificación de las dos industrias y llega hasta la generalización del medio televisivo. Para elaborarla, el autor revisó concienzudamente las fuentes acerca de los cines de los dos países, desde los textos clásicos de Emilio García Riera, Jorge Ayala Blanco, Carlos Monsiváis, Claudio España y Domingo Di Núbila, hasta las publicaciones de los años más recientes hechas por investigadores jóvenes. En la exhaustiva bibliografía final se enlistan alrededor de 300 títulos, que comprenden obras generales o enfocadas en periodos concretos, así como monografías acerca de directores, actores, películas, géneros, etcétera.

Un primer mérito del ensayista peruano León Frías es, entonces, haber hecho un compendio de la información sobre su tema y presentarla de manera coherente, ordenándola de forma cronológica en los seis capítulos y las casi 600 páginas del libro. Esto, por sí solo, ya constituiría una apreciable aportación al conocimiento, pues hasta ahora no existía una obra que mostrara el desarrollo de las dos industrias hecha por un autor único y orientada por los mismos propósito y enfoque; aunque debe apuntarse que hay al menos un volumen colectivo previo que aborda el mismo periodo y buena parte de los mismos temas, tratados desde otras perspectivas, y con el que naturalmente el autor dialoga a lo largo de su libro: Pantallas transnacionales. El cine argentino y mexicano del periodo clásico, editado por Ana Laura Lusnich, Alicia Aisemberg y Andrea Cuarterolo.

Pero Más allá de las lágrimas tiene el agregado de la pasión que León Frías muestra por los cines de los que escribe, lo que presta a su texto una vehemencia estilística particular. Además de espléndidamente investigado, este libro se siente por eso vivido, es decir, filtrado por el contacto afectivo con su materia de estudio. No se trata de una simple aportación académica que sintetiza y hace más amplio el conocimiento del campo que aborda: es, también y sobre todo, el ajuste de cuentas personal de un cinéfilo respecto a los géneros, las películas y las estrellas de dos de las cinematografias que lo apasionan.

Los tres primeros capítulos dan cuenta de la constitución de las industrias de México y Argentina, partiendo de sus inicios y hasta los tiempos de consolidación industrial de los años 40. En el trazado de esta trayectoria, el autor se enfoca en las propuestas que resultaron exitosas, en cada caso, de los tres pilares económicos del cine: géneros populares, sistema de estudios y sistema de estrellas. Particular atención se presta a los recorridos de algunos cineastas y en este punto una interesante aportación es la de los cuadros clasificatorios en los que se enumeran las realizaciones hechas por los directores en distintos géneros o subgéneros. Este procedimiento, seguido para las carreras de Manuel Romero, Luis César Amadori, Juan Orol, Juan Bustillo Oro y 




Hugo del Carril, permite advertir la alta proporción en la que estas destacadísimas figuras de los cines de este periodo se ubicaron en los principales planteamientos comerciales de las respectivas industrias, ayudando de hecho a su consolidación; lo que lleva a pensar que, de manera parecida a como ocurrió en Hollywood con John Ford o Alfred Hitchcock, esos y otros cineastas (y aquí salta de inmediato el nombre de Luis Buñuel) pudieron explotar creativamente y a su favor las condiciones impuestas por las productoras, interesadas sobre todo en el éxito económico de las cintas.

$\mathrm{Al}$ abordar a directores, estrellas, géneros y películas emblemáticas, León Frías traza así una radiografía de cómo se llevó a cabo la construcción industrial que, en apenas 20 años, permitió a los dos países postular atractivas identidades cinematográficas, hasta cierto punto complementarias como polos simbólicos de la vida latinoamericana: el campo, en el caso de México; la gran ciudad, en el de Argentina. La manifestación de costumbres, episodios históricos y asuntos sociales era revestida, en cada caso, con ropajes folklóricos y pegajosas canciones que permitían a las cintas elevarse desde sus mercados locales para ser apreciadas en otros sitios. Los productos se hicieron más numerosos, adquirieron cada año más calidad y, hacia mediados de la década de los 40, ya estaban puestas las principales fichas sobre el tablero. En el lado de México, comedias rancheras y melodramas; canciones campiranas y boleros de arrabal; los estudios; María Félix, Dolores del Río, Jorge Negrete, Arturo de Córdova, Cantinflas, Fernando de Fuentes, Juan Bustillo Oro, Miguel Contreras Torres, El Indio Fernández, Gabriel Figueroa. En el de Argentina: comedias urbanas y melodramas; el tango; los estudios; Luis Sandrini, Libertad Lamarque, Hugo del Carril, Pepe Arias, Niní Marshall, Tita Merello, Leopoldo Torres Ríos, Manuel Romero, Mario Soffici, Luis César Amadori, Carlos Schlieper.

Con estos y otros considerables recursos, las dos industrias compitieron por el mercado hispanoamericano. Al respecto, dice León Frías: "no creo que sea pertinente hablar de un 'imperialismo cultural' mexicano y argentino en esos tiempos" (p. 16). Creo, sin embargo, que podría sostenerse la posición algo más moderada de que la circulación internacional de las películas de los dos principales países productores inhibió hasta cierto punto la creación y la distribución de obras locales en sitios que no habían tenido la ventaja de hacer su propia "acumulación originaria" en los años 30. Como sea, a esta lucha por los mercados convenía la incorporación de otros rasgos del paisaje, las costumbres y las tradiciones latinoamericanas, lo que se hizo posible, por ejemplo, a través de la recreación de episodios de las vidas de Simón Bolívar y José Martí, o de adaptaciones de novelas de escritores como Rómulo Gallegos, pero también al incorporarse a la textura visual y auditiva de las películas semblantes y acentos caribeños, y centro y sudamericanos. En este sentido, vale la pena recordar 
El gaucho Mujica (o La justicia de Pancho Villa), cinta dirigida en México en 1939 por Guz Águila y Guillermo Calles, en la que un aguerrido jinete interpretado por el argentino Vicente Padula iba a caballo desde las pampas hasta el desierto de Chihuahua, lo que daba pie a que se mostraran numerosos números folklóricos de los sitios de Latinoamérica por donde pasaba.

Dada la naturaleza multinacional del conjunto de protagonistas de las dos industrias consideradas, León Frías tiene de hecho que rebasar la recreación de los respectivos ámbitos de estas para incursionar en los de otros cines, fundamentalmente el norteamericano y el español; de esta forma explica, por ejemplo, cómo llegaron a México Norman Foster, Luis Buñuel, Carmen Sevilla y Sarita Montiel, o a Argentina Antonio Momplet y Benito Perojo. También sirven esas incursiones para explicar cómo las otras industrias sirvieron eventualmente como virtuales escuelas en periodos como el de la producción hollywoodense en castellano, o como agradecibles espacios laborales para directores e intérpretes que, por los motivos que fueran, no podían continuar con sus carreras ni en los estudios de la Ciudad de México, ni en los de Buenos Aires.

Hasta fines de 1941, los cines de México y Argentina compitieron entre sí. Pero entonces los Estados Unidos ingresaron a la Segunda Guerra, lanzaron una campaña política y cultural panamericanista y todo cambió. En el cuarto capítulo del libro, que se titula "Destinos cruzados: intercambios y confluencias", León Frías describe los pormenores de esta transformación que se manifestaron, entre otras cosas, en un acercamiento entre productores, directores y artistas. En este capítulo, que representa el núcleo de la investigación, se muestran los resultados que configuraron las fuerzas tendidas del sur al norte y del norte al sur, aunque como hace notar el autor y se ha mencionado arriba, estuvieron también involucrados en este proceso individuos de distintas procedencias que aportaron al conjunto acentos y matices folklóricos, a veces de considerable trascendencia. En cualquier caso, dos poderosas industrias que hasta poco antes competían, de pronto se vieron en la posibilidad e incluso en la necesidad de colaborar entre sí. Los resultados no fueron muy abundantes, considerando el volumen de las respectivas producciones previas, pero sí tuvieron puntos destacados y larga trascendencia. Canciones y melodramas fueron quizá su zona de contacto más generosa y en esa zona reinó en México la argentina Libertad Lamarque. Escribe el autor que esta actriz es

...el más sólido puente entre los cines de Argentina y México. Ella logra potenciar el melodrama a un extremo al que antes no se había llegado (...) Los melodramas que protagoniza articulan las modulaciones del relato pasional equilibrando los componentes disociadores (la enfermedad, el vicio, la locura, el crimen) con su contraparte, la integridad en lo más profundo, la generosidad y el desprendimiento El género (combina) (...) además fuentes musicales de uno y otro lado (p. 377). 
No tuvo la misma relevancia el embajador mexicano en la industria del sur, Arturo de Córdova. Y sin embargo el autor considera que bien puede considerarse la contraparte masculina de Lamarque, sobre todo como símbolo de la relación entre las dos cinematografías. "Lo que queremos expresar - dice- es que el vínculo protagónico, muy taquillero, entre Lamarque y De Córdova está inmerso (...) en una onda de lazos binacionales que no se encuentra en ningún otro de los intérpretes y, si abarcamos un poco más, tampoco de los realizadores de los dos países” (p. 409). Podríamos quizá extender la reflexión para decir que estos intérpretes tal vez fueron percibidos de algún modo como exiliados modélicos, en un periodo en que la búsqueda de un sitio más seguro para vivir y trabajar que los propios países se manifestó con particular intensidad por la guerra civil española, la segunda guerra mundial y ciertas situaciones políticas americanas.

$\mathrm{El}$ autor postula que algunas películas funcionaron como "puentes" entre las dos cinematografías, por su carácter binacional, como el melodrama social Dios se lo pague (1947) de Luis César Amadori, con Arturo de Córdova y Zully Moreno; como Ansiedad (1953) y Escuela de música (1955), dirigidas por Miguel Zacarías, en las que aparecieron como protagonistas Libertad Lamarque y Pedro Infante, o como Historia de una mala mujer (1947) y La corona negra (1951), en las que Luis Saslavsky dirigió, respectivamente, a Dolores del Río y María Félix. En este punto yo añadiría otras cintas de producción argentina: De Méjico llegó el amor Richard Harlan, 1940) y Melodías de América (Eduardo Morera, 1942), en las que Tito Guízar y José Mojica interpretaban, respectivamente, a mexicanos que viajaban al sur del continente y se relacionaban afectivamente con chicas argentinas, así como La amada inmóvil (Luis Bayón Herrera, 1945), que recreaba episodios de la vida del poeta nayarita Amado Nervo.

Además de las afinidades, también se establecen en este libro diferencias entre los dos conjuntos de profesionales, como "la dotación femenina en el cine mexicano de los años cincuenta (...), uno de los argumentos más poderosos del atractivo que (...) siguió teniendo esa cinematografía en el contexto de la región” (p. 317); o, en otro sentido, como la adaptabilidad laboral de realizadores provenientes del sur (Hugo Fregonese, Tulio Demicheli, Luis César Amadori, León Klimovsky, Luis Saslavsky) quienes pudieron ubicarse en las industrias norteamericana, mexicana y española, "cosa que no hizo ningún mexicano en el periodo clásico, a no ser de manera esporádica" (p. 429) - probablemente, añadimos, porque no lo necesitaron, es decir, porque su propia industria les procuró condiciones laborables atractivas y suficientes. 
Los capítulos quinto y sexto ofrecen de nuevo las trayectorias de las dos cinematografías, describiendo los procesos, ocurridos en los años 50 y principios de los 60 , que condujeron al agotamiento del modelo de las llamadas "épocas de oro". Se abordan en ellos, sobre todo, las estrategias seguidas en México y Argentina para enfrentar el considerable reto impuesto por el surgimiento y el desarrollo de la industria de la televisión. Películas eróticas, de terror, de lucha libre y wésterns se dan cita en este par de capítulos para mostrar los intentos que marcaron el fin de un largo ciclo contra el que se elevaría pronto el movimiento de los nuevos cines, de la mano de las transformaciones culturales impulsadas en la región por la triunfante revolución cubana.

En distintos momentos de esta obra, el autor llama la atención sobre personalidades que resultan trascendentes para la historia contada. Naturalmente está todo lo que se necesita saber acerca de las estrellas y los directores de primer orden que participaron en las dos cinematografias; pero también hay anotaciones relativas a figuras secundarias que, vistas desde otras perspectivas, no han suscitado mayor atención. Por ejemplo, León Frías apunta que habría que estudiar "con cierto detenimiento" la aportación realizada por el argumentista Edmundo Báez a los melodramas mexicanos y en particular a los que escribió para cintas con Libertad Lamarque (p. 372); también afirma que el director Antonio Momplet, quien inició y terminó su carrera en España, pasando por Argentina y México, requiere de una "merecida revisión", al ser uno de los cineastas "que oficiaron de responsables de la puesta en imágenes de tantas películas en los países del norte y del sur” (p. 389). Entre los vasos comunicantes que atraviesan Más allá de las lágrimas, uno de los más disfrutables es la atención que prodiga el autor a la información sobre la música de las películas. Y no solo a los tangos interpretados por Carlos Gardel, Libertad Lamarque, Tita Merello y Hugo del Carril, los boleros de Agustín Lara y las canciones rancheras de Tito Guízar, Jorge Negrete y Pedro Infante, sino también a lo que llama el "mestizaje musical latinoamericano", incorporado a las películas con los bongoceros y las bailarinas cubanas, y las cantantes españolas Carmen Sevilla, Lola Flores y Sarita Montiel, entre otros.

Puede concluirse que el propósito de León Frías de ofrecer un panorama histórico completo de las cinematografías de Argentina y México en el periodo que aborda queda más que cumplido. El autor anuncia además un segundo volumen, en el que estudiará "los esquemas genéricos, narrativos y audiovisuales" que permiten hablar de "un modelo común o, al menos, similar" (p. 18) entre las dos industrias, modelo al que podría denominarse, precisamente, el del "cine clásico". Quedamos a la espera de esta nueva obra, que promete ser tan interesante como la que aquí se reseña. 


\section{Bibliografía}

Ángel Miquel (México) es Profesor de la Facultad de Artes de la Universidad Autónoma del Estado de Morelos y egresado del doctorado en Historia del Arte de la UNAM. Se especializa en el estudio del cine mexicano y su cultura. También ha incursionado en la escritura de ficción. Entre sus libros recientes se encuentran el ensayo Crónica de un encuentro: el cine mexicano en España, 1933-1948 (UNAM, 2016) y la novela Tolvanera (Ediciones Sin Nombre y Secretaría de Cultura, 2017).

León Frías, I. (2018). Más allá de las lágrimas. Espacios habitables en el cine clásico de México y Argentina. Lima, Perú: Universidad de Lima.

Lusnich, A. L., A. Aisemberg y Cuarterolo, A. (Eds.) (2017). Pantallas transnacionales. El cine argentino y mexicano del periodo clásico. Buenos Aires, Argentina: Imago Mundi y Cineteca Nacional de México. 